\title{
IMPLEMENTASI SISTEM INFORMASI MANAJEMEN KEPEGAWAIAN PADA PEMERINTAH DAERAH DI MASA COVID-19: STUDI LITERATUR
}

\author{
Ilham Mariyanto ${ }^{1}$, Supriansyah ${ }^{2}$ \\ ${ }^{1}$ Universitas Muhammadiyah Prof. DR. HAMKA \\ ${ }^{2}$ Universitas Muhammadiyah Prof. DR. HAMKA \\ Email: ${ }^{1}$ mariyantoilham23@gmail.com, ${ }^{2}$ supriansyah@uhamka.ac.id
}

(Naskah masuk: 1 Agustus 2021, diterima untuk diterbitkan: 16 Agustus 2021)

\begin{abstract}
Abstrak
SIMPEG mencakup data pegawai, pengelolaan data, perjalanan, manusia dan teknologi serta dukungan departemen sumber daya manusia supaya menyediakan layanan yang cepat, lengkap, dan tepat. Dalam implementasi SIMPEG selama pandemi covid-19 di pemerintah daerah masih mengalami permasalahan seperti user, admin, sistem, dan birokrasi. Penelitian ini bermaksud untuk menjelaskan factor-faktor permasalahan ini serta rekomendasi terkait digitalisasi pada data pegawai pemerintah daerah selama masa covid19 dengan rincian; 1) Mendeskripsikan faktorfaktor yang menghambat penerapan digitalisasi data pribadi (SIMPEG) diintansi pemerintah daerah selama masa covid-19, 2) Mendeskripsikan upaya-upaya yang dilakukan untuk menggalakkan SIMPEG di instansi pemerintah daerah selama pandemic covid-19. Peneliti mengkaji dan menganalisis berbagai sumber penelitian sebelumnya dengan menerapkan kaidah penelitian studi literatur. Hasil penelitian SIMPEG dimasa pandemi covid-19 belum optimal, dilihat belum adanya standar kualifikasi bagi pegawai yang menangani SIMPEG, pemrosesan data pegawai masih dilakukan secara manual, kebijakan pimpinan belum terukur, dan daya tangkap pegawai masih bermasalah, belum adanya evaluasi dalam upaya peningkatan kapasitas sarana jaringan dan anggaran operasional, terdapat permasalahan teknis operasional. Upaya-upaya dalam menggalakkan SIMPEG dimasa pandemi covid-19 yaitu perlunya upgrade sistem untuk memudahkan tugas, peningkatan pengadaaan sarana dan prasarana terkait IT, pengadaan SDM tenaga ahli, pembuatan prosedur, peningkatan anggaran operasional, pendidikan dan pelatihan, jaminan keamanan dan kerahasiaan data, pemantauan oleh pimpinan, sinyal atau koneksi internet. Peneliti memberikan saran berupa Pengembangan menu SIMPEG agar menciptakan layanan yang sangat baik, memberikan pelatihan terkait penggunaan SIMPEG secara offline maupun online yang dianggarkan oleh pemerintah daerah, dan upaya-upaya peningkatan digitalisasi data kepegawaian dengan peremajaan perangkat maupun sistem di lingkungan instansi kepegawaian pemerintah.
\end{abstract}

Kata kunci: Implementasi SIMPEG, Pemerintah Daerah, Covid-19, Studi Literatur

\section{IMPLEMENTATION SYSTEM INFORMATION MANAGEMENT EMPLOYEE ON LOCAL GOVERNMENT ON TIME COVID-19 : A LITERATURE REVIEW}

\begin{abstract}
SIMPEG includes employee data, data management, travel, human and technology as well human resources department support to provide fast, complete, and precise services. In the implementation of SIMPEG during the covid-19 pandemic in local governments still experience problems such as user, admin, system, and bureaucracy. This study intends to explain the factors of this problem as well recommenendations related to digitalization of local government employee data during the covid-19 period with details; 1) describing the factors that hinder the implementation of digitalization personal data SIMPEG, 2) describing the efforts made to promote SIMPEG in local government agencies during the covid-19 pandemic. Researchers review and analyze various sources of previous research. SIMPEG research results during the covid-19 pandemic have not been best. There is no qualification standard for employees who handle SIMPEG, employee data processing is still done manually, leadership policies have not been measured, and employee arrest power is still problematic, the is no evaluation in an effort to increase the capacity of network facilities and operasional budget. There are operational technical problem. Effort in promoting SIMPEG during the covid-19 pandemic are the need for system upgrade to facilitate task, improved provision of IT related facilities and insfrastructure, procurement of expert human resource, making procedures, increasing operational budget, education and training, guaranteeing security and confidentiality of data, monitoring by leaders, signal or internet connection. Research provide advice in the form of SIMPEG menu development in order to create excellent service, provide training related to the use of SIMPEG offline and online
\end{abstract}


budget by the local government, and effort to improve the digitalization of staff data with the rejuvenation of device and system in the government staffing agencies.

Keywords: SIMPEG Implementation, Local Government, Covid-19, A Literature Review.

\section{PENDAHULUAN}

Pemanfaatan teknologi informasi dalam segala kegiatan administrasi bertujuan untuk mewujudkan good governance. Rancangan good governance membutuhkan suatu sistem yang dapat memenuhi tuntutan servis agar efektif serta efisien. Sistem informasi dapat digunakan untuk mengotomatisasi tugas dan fungsi departemen untuk menciptakan departemen yang unggul, pendukung keputusan termasuk otomatisasi manajemen sistem .[1]

Implementasi kebijakan e-government menjadikan bagian dari upaya dalam pengembangan e-government. Perkembangan dan penggunaan teknologi informasi telah menciptakan revolusi dalam penggunaan internet yang semakin meluas sebagai akses ke dunia maya. Selain transmisi dan penikmatan hiburan, perubahan penggunaan teknologi informasi juga diterapkan dalam dimensi lain berupa proses regulasi pemerintah dalam meningkatkan kualitas layanan publik.[2] Implementasi kebijakan e-government dilakukan dengan pengoptimalan dalam penggunaan kemajuan pada TI dan meminimalisir hambatan baik organisasi maupun birokrasi.

Prosedur dalam mengimplementasikan egovernment mesti didukung oleh prasarana kelembagaan yang mampu dikenali dan dibangun oleh lembaga, sebagaimana mestinya, untuk mencapai tujuan mereka. Infrastruktur kelembagaan meliputi koordinasi antar lembaga, peningkatan kerjasama, dan komunikasi yang baik antar lembaga terkait.[3] Sistem informasi sumber daya manusia dirasa sangat penting dalam melayani seluruh pegawai yang ada, karena pegawai merupakan faktor terpenting dalam operasional instansi pemerintah. Manajemen yang baik dari sejumlah kecil karyawan berarti lebih banyak staf, yang akan meningkatkan kinerja seluruh pemerintah.

Saat ini, berbagai bidang kehidupan beralih ke digital untuk efisiensi dan pengoptimalan. Ini termasuk digitalisasi sektor telekomunikasi, penyiaran dan data pemerintah, dalam hal ini SIMPEG juga berperan penting.

Dengan dibentuknya SIMPEG di tahun 2006, pegawai sebagai sumber daya yang bekerja pada instansi pemerintah dengan tugas utamanya mengembangkan dan melaksanakan kebijakan SDM daerah yang menguraikan pentingnya untuk mengatur dan memelihara informasi karyawan. [4] SIMPEG juga dinilai sangat penting untuk melayani semua staf yang ada. Karyawan atau pegawai merupakan unsur sumber daya terpenting dalam operasional sebuah organisasi yang harusnya dikelola dengan baik. Manajemen karyawan yang akurat pada rentang yang sempit dalam meningkatkan performa karyawan dan, pada rentang yang semakin luas, mengarah pada peningkatan keseluruhan dalam kinerja bisnis / pemerintah. Pada dasarnya, SIMPEG berperan dalam membantu, menunjang dan menyediakan data informasi karyawan yang akurat. Data seluruh PNS terupdate dan menjadi database. Kegunaan database ini adalah untuk mengelola kebutuhan karyawan akan mobilitas, promosi, mutasi, cuti, gaji dan tunjangan lainnya.[5]

Mengingat pentingnya pengelolaan data pegawai, maka penyusunan SIMPEG sendiri bertujuan untuk memajukan kualitas pengelolaan SDM untuk mewujudkan prioritas dalam tahap pengembangan. Tahap pengembangan e-Government ini sangat cocok untuk Sistem Informasi Kepegawaian (SIMPEG) khususnya pada masa pandemi Covid-19 untuk memahami faktor dan upaya digitalisasi pegawai pemerintahan daerah.

Dapat diketahui bahwa aplikasi Sistem Informasi Manajemen Kepegawaian adalah sistem dengan kemampuan untuk terlibat dalam bidang sumber daya manusia, menambah, mempertahankan dan memperkaya pengetahuan dan memberikan pengetahuan personel kepada mereka yang membutuhkannya. Sebagai penentu keputusan yang akurat pada waktu yang tepat.[6]

Sistem informasi manajemen kepegawaian dikerahkan dengan cepat, dan akurat sebagai pendukung kebijakan pengelolaan pegawai negeri sipil[7]. Disini kondisi SIMPEG umumnya belum terupdate secara otomatis, sehingga cepat dan mudah untuk memperoleh data tentang karyawan yang dibutuhkan di setiap bagian dalam proses pelatihan. Upaya peningkatan kualitas pekerja, selain lambat, tidak dapat ditutupi secara seragam.

SIMPEG sebagai alat yang terdiri dari perangkat pengolah data, pengumpul data, prosedur, tenaga pengolah data, dan perangkat lunak. Perangkat penyimpanan yang berisi pusat data serta perangkat komunikasi yang saling berkaitan satu dengan yang lain, implikasi dan saling menentukan sebagai hal dalam mengupayakan bagi penyedia informasi di bidang kepegawaian. Database yang berisi sekumpulan data seluruh pegawai dan bermanfaat bagi perencanaan dan pelaksanaan pendayagunaan aparatur negara di Departemen dalam negeri dan Pemerintah Daerah.[8]

SIMPEG, adalah aplikasi yang menyediakan informasi kepegawaian, mendukung pengelolaan data kepegawaian dengan berbagai keunggulan.[5] Artinya pengolahan data di komputer dapat melakukan pengolahan data informasi SDM dengan cepat, informasi yang diolah dengan berbagai validasi 
dan pengecekan menjadi akurat dan jauh lebih tepat. Itu disimpan pada media penyimpanan yang dapat di akses kapan saja sehingga kita dapat mencari dengan mudah dan cepat. Otentikasi pengguna dan otentikasi tingkat pengguna membuat informasi user lebih aman dan hanya dapat diakses oleh pengguna yang berwenang. Mengelola informasi pribadi relatif mudah, hal ini dapat digunakan untuk mengukur produktivitas karyawan selama pemrosesan dan pelaksanaan prosedur perekrutan pada pemerintah daerah.

PEMDA dan DPRD mengatur penyelenggaraan pemerintahan berdasarkan asas otonomi dan pemerintahan bersama, dan asas otonomi yang seluas-luasnya dalam sistem tersebut.[9]

Tujuan keberadaan lembaga atau perangkat negara adalah untuk menjalankan fungsi negara dan sebenarnya menjalankan fungsi pemerintahan. Organisasi-organisasi tersebut harus mampu membentuk proses integrasi yang saling berhubungan secara fungsional.[10]

Sistem pemerintahan daerah memiliki beberapa aturan dasar pembagian kekuasaan, seperti aturan pembagian kekuasaan horizontal dan aturan pembagian kekuasaan vertikal. Tafsir UU no. 23 Tahun 2014 tentang PEMDA.[11] Asas pemerintahan daerah memiliki tujuan dan cita-cita yang terkandung dalam undang-undang yang mengatur tentang otonomi daerah dan harus bertujuan untuk meningkatkan kesejahteraan masyarakat, memperhatikan kepentingan dan aspirasi dari masyarakat.

Hasil temuan studi literatur dalam pelaksanaan SIMPEG dinilai sudah mengalami perubahan dan dapat berkomunikasi dengan sistem yang lainnya, dalam beberapa kasus masih terdapat faktor-faktor yang menghambat cukup signifikan, dilihat dari user yang mengeluhkan sistem yang bermasalah, low signal dan tingkat keamanan yang diragukan sehingga masih diperlukan tindak lanjut agar dapat meminimalisir resiko tersebut.[5] User dinilai kurang mumpuni ketika terjadi kendala dalam penggunaanya, hal tersebut masih dibutuhkannya pengarahan atau bimbingan secara Teknik dalam mengaplikasikan SIMPEG.

Penelitian ini merupakan studi literatur yang mengungkapkan faktor-faktor penghambat SIMPEG di saat pandemi covid-19 dan mendeskripsikan upaya-upaya dalam menggalakkan SIMPEG di pemerintah daerah selama pandemi covid-19. Harapannya penelitian ini dapat menjadi modal dan bahan evaluasi terhadap SIMPEG yang sudah di implementasikan maupun pengembangan SIMPEG agar lebih terukur dengan tujuan menghindari kegagalan.[12]

\section{METODE PENELITIAN}

Jenis studi yang dipakai adalah studi literatur. Metode pencarian literatur adalah serangkaian kegiatan yang berkaitan dengan cara data perpustakaan dikumpulkan, dibaca, dicatat, dan dikelola. Dengan mempelajari literatur dengan cara ini, peneliti dapat secara efektif membangun landasan teori, struktur pertimbangan dan hipotesis dari berbagai sumber (sebaiknya direvisi) tanpa mengurangi aspek akademik.[13]

Sistem literatur yang digunakan untuk mengetahui implementasi simpeg pemerintah daerah saat masa pandemi covid-19 mengacu pada penelitian-penelitian tahun 2019-2021, dan secara umum untuk mencari jawaban atas permasalahanpermasalahan SIMPEG yang ada di pemerintah daerah berdasarkan data mutakhir 10 tahun belakangan.

\section{HASIL DAN PEMBAHASAN}

\subsection{Faktor-faktor Penghambat Implementasi SIMPEG Selama Pandemi Covid-19}

Sistem Informasi Sumber Daya Manusia (SISDM) SIMPEG dinilai penting untuk melayani seluruh staf yang ada. Karyawan merupakan aset organisasi yang penting yang harus dijalankan dengan teratur. Manajemen karyawan yang baik di area mini meningkatkan kinerja karyawan dan sebagian besar meningkatkan kinerja bisnis/pemerintah secara menyeluruh. Mengingat urgensi pengelolaan data pegawai, maka peningkatan kualitas pengelolaan sumber daya manusia dengan menyiapkan rekrutmen sebagai pengelolaan SDM menjadi salah satu prioritas dalam tahap pengembangan kebijakan.[14]

Dalam 6 rangkuman literatur, ditemukan faktorfaktor penghambat dalam implementasi SIMPEG disaat pandemi covid-19 [5][15][16][17][18][19] diantaranya; data pegawai yang fluktuatif dan dinamis, SDM yang belum mumpuni dalam pengelolaan, koordinasi antar bidang yang belum maksimal, dibutuhkannya pengawasan dalam pelaksanaannya, belum ter-upgradenya data pegawai, user yang malas karena sistem mengalami masalah, kebijakan pimpinan terkait SOP, sarana dan prasarana yang dinilai masih kurang mumpuni, belum adanya evaluasi secara periodik.

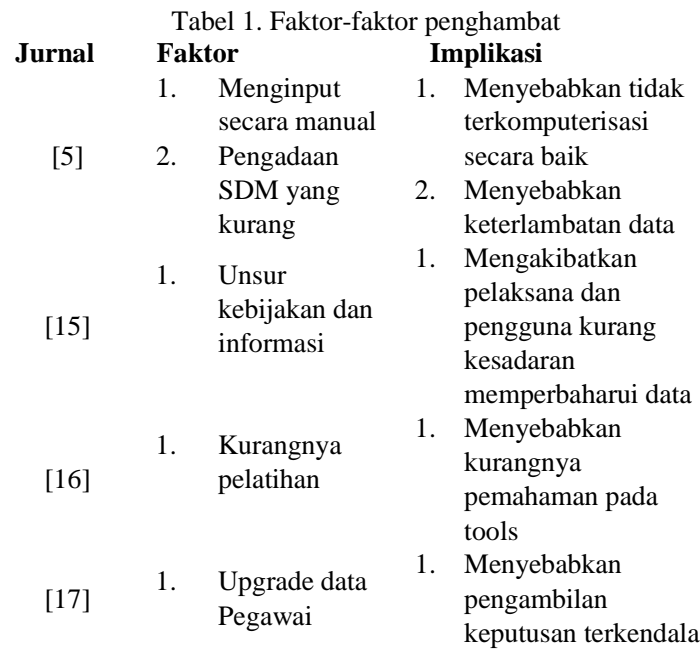




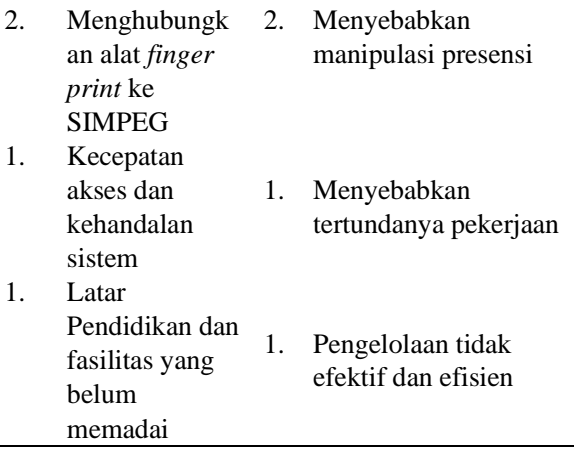

Temuan lainnya membahas faktor penghambat pelaksanaan SIMPEG belum optimal, dalam komponen proses input data masih terkendala dengan jaringan.[20]

Pada beberapa instansi pemerintah kota masih mengalami masalah dalam menghadapi aksesbilitas terhadap layanan SIMPEG, hal tersebut dibuktikan bahwa dalam proses administrasi masih terhalang oleh birokrasi dan belum sepenuhnya diberikan tanggungjawab kepada user[21]

\subsection{Upaya-upaya Dalam Menggalakkan SIMPEG Selama Pandemi Covid-19}

Berdasarkan peristiwa selama masa pandemic covid-19, diperlukan upaya dalam menggalakkan SIMPEG, salah satunya adalah transisi digital. Transisi ke digital saat ini sedang berlangsung di berbagai bidang kehidupan dengan tujuan efektif, efisien dan optimal. Hal ini termasuk digitalisasi sektor penyiaran, telekomunikasi dan data pemerintah. Berlandaskan definisi tersebut, penulis dapat menyimpulkan bahwa digitalisasi merupakan cara penyediaan atau penggunaan sistem secara digital.

Digitalisasi diselenggarakan untuk mengarsipkan dokumen dalam format digital dan memiliki fungsi menyalin dan membuat koleksi perpustakaan digital. Proses digitalisasi membutuhkan peralatan seperti komputer, pemindai, operator media sumber, dan perangkat lunak pendukung. Dokumen tercetak dapat dikonversi ke format digital menggunakan program pemindaian dokumen contohnya seperti Adobe Acrobat atau Omnipage. Pemrograman program pemrosesan audio seperti CoolEdit atau JetAudio untuk mengonversi dokumen audio Anda ke format digital. Dokumen video dapat dikonversi ke format digital menggunakan program pemrosesan video.[22]

Tabel 2. Proses digitalisasi dokumen dan peralatan yang digunakan (Sumber : Dhani Sugiharto, 2010)

\begin{tabular}{cccc}
\hline No & $\begin{array}{c}\text { Jenis } \\
\text { Dokumen/Ar } \\
\text { sip }\end{array}$ & $\begin{array}{c}\text { Proses } \\
\text { Digitalisasi }\end{array}$ & Peralatan \\
\hline 1 & Foto & Scanning & $\begin{array}{c}\text { Flatbed scanner atau } \\
\text { kamera set pada meja } \\
\text { flatbed }\end{array}$ \\
2 & Peta & Scanning & $\begin{array}{c}\text { Scanner khusus peta } \\
\text { atau kamera set pada } \\
\text { meja flatbed }\end{array}$ \\
\hline
\end{tabular}

\begin{tabular}{|c|c|c|c|}
\hline 3 & Kertas & Scanning & $\begin{array}{c}\text { Flatbed Scanner atau } \\
\text { kamera set pada meja } \\
\text { flatbed }\end{array}$ \\
\hline 4 & $\begin{array}{l}\text { Mikrofilm } \\
\text { dan } \\
\text { Mikrofiche }\end{array}$ & Scanning & $\begin{array}{l}\text { Digital Microfilm } \\
\text { Scanner }\end{array}$ \\
\hline 5 & Kaset Audio & $\begin{array}{c}\text { Digital } \\
\text { Recording }\end{array}$ & $\begin{array}{l}\text { Komputer, digital, } \\
\text { audio recorder }\end{array}$ \\
\hline 6 & Kaset Video & $\begin{array}{c}\text { Digital } \\
\text { Recording }\end{array}$ & $\begin{array}{c}\text { Komputer, Direct } \\
\text { VCD/DVD Recorder }\end{array}$ \\
\hline
\end{tabular}

SIMPEG juga dapat membantu memberikan informasi yang digunakan sebagai acuan dalam pengambilan keputusan sebagai pengelolaan manajemen kepegawaian.[23] Dari hasil review[24][15][16][20][17] peneliti dapat menginterpretasikan bahwa upaya-upaya yang dapat dilakukan untuk menggalakkan SIMPEG dimasa pandemi covid-19 yaitu pengembangan SIMPEG dengan penambahan modul cuti dan mutasi, peningkatan kuantitas dan kualitas pengelola program SIMPEG, peningkatan sarana dan prasarana terkait dengan teknologi informasi, melakukan penganggaran mengenai pendidikan dan pelatihan, membuat kebijakan terkait SOP, dan melakukan pengawasan.

SIMPEG tingkat pemerintah daerah selalu menggunakan sistem sendiri dari pada sistem pemerintah pusat, karena tidak ada instruksi secara langsung dari pemerintah pusat. Digitalisasi bertujuan tidak lebih dari mencapai efisien dan optimal dalam banyak hal, termasuk efisien dan optimal ruang penyimpanan, keamanan terhadap beragam jenis ancaman, resolusi tinggi, gambar, dan suara yang lebih stabil. SIM terkomputerisasi adalah SIM yang menempatkan peralatan komputer untuk pemrosesan data di lokasi-lokasi kritis[25] contohnya SIMPEG yang berlokasi di BKD Provinsi Jawa Timur.[23]

SIMPEG pemerintah daerah dengan sistem server lokal atau sistem offline. Memang, kerusakan apa pun mudah diperbaiki, sementara kerusakan publik dapat diakses melalui sistem online. Hanya ada satu server di ruang khusus, dari mana jaringan lokal (localhost) terhubung ke setiap BKD Kabupaten Sidoarjo. Dengan 55 klien atau pengguna, akses disesuaikan dengan tugas masing-masing.[26]

Indikator keberhasilan SIMPEG pemerintah daerah dapat dilihat dari hasil penelitian yang dilakukan [18] menunjukkan bahwa SIMPEG mecapai persentase 78,22\% dan masuk dalam interval 61\%-80\% dengan kategori baik. Pada literatur [15], [16]mengemukakkan bawa SIMPEG sudah berjalan cukup baik.

Selama tahap pengembangan SIMPEG di pemerintah daerah, memiliki unsur yang saling berkorelasi dan digunakan dalam memproses informasi sesuai dengan kepentingan institusi. Faktor-faktor ini secara signifikan berpengaruh pada fungsi sistem informasi dalam pelaksanaan input, proses, output, pengarsipan dan pemantauan. Untuk 
mengalihkan sumber daya data menjadi produk informasi komponen tersebut adalah:
a) Hardware
b) Perangkat lunak
c) Basis Data
d) Jaringan (perangkat lunak jaringan)

e) Selama implementasi dan pengembangan sumber daya manusia (Software Otak)

Unsur dari SIMPEG ini saling terkait untuk mewujudkan tujuan SIMPEG untuk memudahkan karyawan dalam mengelola dan menggunakan data dalam memutuskan. Dalam penelitian ini, peneliti mendeskripsikan bermacam-macam komponen tersebut digunakan untuk menunjang implementasi dan pengembangan SIMPEG. Dalam pengelolaan kepegawaian ditemukan hasil bahwa performa akan lebih efisien dengan SIMPEG ini, dimana pengembangan tools SIMPEG diperlukan seperti penyesuaian letak dan ukuran yang dibersarkan sedikit agar user dapat melihat dengan jelas.[27]

Berdasarkan hasil literatur [28], disimpulkan bahwa hasil yang dihasilkan oleh SIMPEG di pemerintah daerah adalah sebagai berikut:
a) Data pegawai
b) Rangkuman jumlah pegawai
c) Nama pegawai
d) Nama pensiunan pegawai

Hasil yang dihasilkan oleh SIMPEG di pemerintah daerah berguna dalam kasus-kasus berikut:

a)Untuk memudahkan proses pencatatan dan pengumpulan data dari pegawai

b) Memudahkan dokumentasi dan akses ke database pegawai

c) Memfasilitasi pengambilan dan pencetakan data untuk laporan

d) Menurut keputusan orang pendukung.

Pemerintah daerah menerapkan SIMPEG dalam mendukung manajemen sumber daya manusia dalam mendukung survei yang dilakukan, implementasi SIMPEG membantu pemerintah daerah untuk mengolah data kepegawaian untuk pemerintah kota Salatiga secara cepat, akurat dan komprehensif [29]. Studi serupa menunjukkan penerapan sistem informasi talenta dapat mengontrol perilaku talenta dan mempercepat pengambilan keputusan karyawan.[30]

Anggaran pengembangan SIMPEG digunakan, sehingga implementasi sistem informasi pegawai selama pandemi Covid-19 dalam hal,

a) Mendukung sistem manajemen PNS dan pengembangan sumber informasi kepegawaian yang tepat di instansi pemerintah.

b) Data di bagian kepegawaian diperbarui dan menyatu.

c) Memberikan informasi yang akurat tentang pegawai pemerintah dengan tujuan pengembangan, kesejahteraan, perencanaan dan pengelolaan pegawai pemerintah serta dukungan pekerjaan yang baik di area pegawai pemerintah daerah.
Hasilnya terdapat langkah yang baik menuju EGoverment pembangunan SIMPEG di pemerintah daerah tidak lepas dari efisiensi di bidang manajemen sumber daya manusia. Integrasi teknologi informasi dapat memudahkan terciptanya database yang akurat dan up-to-date dalam peningkatan pelayanan dan pengolahan data di bidang SDM.[31]

Pemutakhiran data pegawai negeri secara berkala. Tambahkan fungsi atau izin dari menu akses. Dalam pendekatan sistem, sistem terkait dengan subsistem lain dari organisasi. Di sisi lain, dalam pemerintahan negara bagian, pemerintah adalah organisasi yang sangat banyak dan stafnya adalah salah satu subsistemnya. Organisasi besar sering menyimpan catatan individu yang terkomputerisasi. SIMPEG adalah aplikasi perangkat lunak yang digunakan untuk mengelola data pegawai di lingkungan pemerintah daerah yang terintegrasi dan komprehensif. SIMPEG juga dapat berfungsi sebagai monitoring dan evaluasi kepegawaian yang dapat memudahkan sistem pelaporan, sehingga tidak diperlukan lagi sistem pengawasan sejenis.[32]

Sistem informasi manajemen personel Departemen Dalam Negeri dan PEMDA, sistem informasi untuk mengelola personel yang ditugaskan ke personel dan perangkat lunak untuk pengumpulan, prosedur, dan penanganan; pusat data dan database untuk perangkat penyimpanan Dan perangkat komunikasi saling bergantung, bergantung, dan saling ditentukan dalam konteks penyampaian info personel.[33]

\section{KESIMPULAN}

Peneliti menarik kesimpulan yang ditulis pada artikel ilmiah Implementasi Sistem Informasi Kepegawaian pada Covid-19 dapat disimpulkan sebagai berikut:

1. Sistem digitalisasi data arsip pegawai negeri adalah SIMPEG berbasis web. Hal ini karena kerusakan mudah diperbaiki dan dapat dilihat secara publik memakai sistem online. Dengan SIMPEG ini, pekerjaan akan lebih efisien dan efektif. Perkembangan tools SIMPEG diperlukan berdasarkan penggajian otoritas lokal dan analisis layanan yang sangat baik. Indikator keberhasilan SIMPEG pemerintah daerah dapat dilihat dari tingkat keakuratan dan validitas data lapangan menggunakan database SIMPEG.

2. Elemen mendukung implementasi SIMPEG agar dapat berfungsi dengan baik dengan memberikan pelatihan IT untuk SIMPEG yang ada. Adanya bantuan anggaran administrasi dari bupati setempat berarti program SIMPEG akan konsisten dimutakhirkan sesuai karakteristik yang dibutuhkan. Minimnya kesadaran ASN terkait pemutakhiran data menjadi kendala yang menghambat program SIMPEG.

3. Upaya peningkatan digitalisasi data kepegawaian di lingkungan lembaga kepegawaian pemerintah daerah telah 
diselenggarakan, antara lain pendokumentasian kekurangan fungsi program SIMPEG dan pembuatan aplikasi yang lebih kompleks sehingga memudahkan pegawai dalam menjalankan fungsi pegawai.

\section{DAFTAR PUSTAKA}

[1] H. Agustin., 2019. Sistem Informasi Manajemen dalam Perspektif Islam: 1st ed., no. 1. PT. Raja Grafindo Persada. Depok

[2] S. Budhirianto, "Implementasi Electronic Government Di Provinsi Jawa Barat,” 2012, no. 1, p. 169.

[3] Indrajit, "Naskah Akademik dan Rancangan Peraturan Daerah tentang Pengelolaan EGovernment di Provinsi Sumatera Barat," EGov., p. 91, 2017.

[4] A. C. Pardede and M. Mustam, "Manajemen Sumber Daya Manusia Pegawai Negeri Sipil Dalam Rangka Reformasi Birokrasi Di Kabupaten Semarang Oleh: Annetta Carolina Pardede, Mochammad Mustam," J. UNDIP, 2017.

[5] S. Komalasari, I. Hanafi, and E. Setyowati, "Aplikasi Program Sistem Informasi Manajemen Kepegawaian (SIMPEG) (Studi pada Badan Kepegawaian Daerah Kota Malang)," Adm. Publik, vol. 2, no. 4, pp. 613$619,2019$.

[6] T. W. Ramdhani, B. Purwandari, and Y. Ruldeviyani, "The Use of Data Mining Classification Technique to Fill in Structural Positions in Bogor Local Government," 2016.

[7] P. Sudjiman and L. Sudjiman, "Analisis Sistem Informasi Manajemen Berbasis Komputer dalam Proses Pengambilan Keputusan," TeIKa, vol. 8, no. 2, pp. 55-66, 2018.

[8] Keputusan Menteri Dalam Negeri Nomor 17 Tahun 2000.

[9] Undang-Undang No 32 Tahun 2004 Tentang Pemerintah Daerah. 2004

[10] L. Eddyono, "Penyelesaian Sengketa Kewenangan Antar Lembaga Negara Oleh Mahkamah Konstitusi," DiH J. Ilmu Huk., vol. 10, no. 19, 2014, doi: 10.30996/dih.v10i19.284.

[11] Undang-Undang Nomor 23 Tahun 2014 tentang Pemerintahan Daerah. 2014.

[12] A. R Pamungkas, L. Edi Nugroho, and S. Sulistyo, "Evaluasi Faktor Kegagalan Sistem Informasi Pada Kesiapan Penerapan EGovernment: Studi Literatur," JIKO (Jurnal Inform. dan Komputer), vol. 3, no. 3, pp. 143 152, 2020, doi: 10.33387/jiko.v3i3.2176.

[13] E. D. Kartiningrum, "Panduan Penyusunan Studi Literatur," Lemb. Penelit. dan Pengabdi. Masy. Politek. Kesehat. Majapahit, Mojokerto, pp. 1-9, 2015.

[14] L. Thi, T. Huong, G. M. Pomeroy, and A. U. Conference, "Proceedings of the 15th
International Asian Urbanization Conference,' 2019, p. 570 : Springer. Vietnam.

[15] A. A. G. R. dan I. M. M. Wayan Dharmawan, "Implementasi Program Sistem Informasi Manajemen Kepegawaian (SIMPEG) berbasis web di Badan Kepegawaian dan Pengembangan Sumber Daya Manusia (BKPSDM) Kabupaten Badung," Adm. Publik, 2019.

[16] A. Sadat, "Implementasi Sistem Informasi Manajemen Kepegawaian (SIMPEG) Pada Dinas Kesehatan Kabupaten Aceh Tenggara," Bul. Utama Tek., vol. 14, no. 3, pp. 200-204, 2019.

https://jurnal.uisu.ac.id/index.php/but/article/vi ew/1273.

[17] R. Para, R. Lambelanova, and E. Indrayani, "Implementasi Kebijakan Penerapan Sistem Informasi Manajemen Kepegawaian (SIMPEG) Dalam Manajemen Pegawai Di Kota Ambon Provinsi Maluku," Visioner, vol. 12, no. 1, pp. 117-124, 2020.

[18] N. Faradilla and F. Niswah, "Kualitas Sistem SIMPEG Online di Badan Kepegawaian dan Pengembangan Sumber Daya Manusia (BKPSDM) Kabupaten Sampang," Publika, pp. $1-6$, 2020. https://jurnalmahasiswa.unesa.ac.id/index.php/ publika/article/view/33389.

[19] D. Widyawan and A. Idris, "Implementasi Sistem Informasi Manajemen Kepegawaian (Simpeg) Di Badan Kepegawaian Pendidikan Dan Pelatihan Kabupaten Musi Rawas," Adm. Reform, vol. 8, no. 2, pp. 125-136, 2020.

[20] F. Haris, Abd. Sumardi. Hamka, "Implementasi Sistem Informasi Manajemen Kepegawaian ( SIMPEG ) Pada Kementerian Agama Kabupaten Sinjai," Sos. dan Polit., 2020, doi: 10.47030/jaq.v10i2.156.

[21] R. Fathur and M. Mamun, "Rancang Bangun Sistem Informasi Manajemen Pegawai (Simpeg) Berbasis Web Pada Kementerian Ppn/Bappenas," IJNS-Indonesian J. Netw. Secur., vol. 8, no. 4, pp. 1-8, 2019.

[22] D. Sugiharto, "Penyelamatan Informasi Dokumen / Arsip Di Era Teknologi Digital," $B A C A$, vol. 31, no. 1, pp. 51-64, 2010.

[23] M. K. Djawa and D. Puspasari, "Implementasi Aplikasi Sistem Informasi Manajemen Kepegawaian (SIMPEG) Untuk Mendukung EGoverment Pada Badan Kepegawaian Daerah (BKD) Provinsi Jawa Timur," J. Adm. Perkantoran, vol. 3, pp. 1-15, 2015.

[24] T. Nurwan, "Pengembangan Sistem Informasi Kepegawaian (SIMPEG) Berbasis Web (Studi Kasus: Subbagian Administrasi Desa Sukatali)," Reg. Public Adm., vol. 4, no. 2, 2019.

[25] Nurdin and R. Arifin, "Kontribusi Sistem Informasi Manajemen Berbasis Komputer Terhadap Kinerja Pegawai Pusdik Intelkam Polri Bandung," Edutech, vol. 13, no. 2, p. 246, 
2014, doi: 10.17509/edutech.v13i2.3107.

[26] A. Jurachman, "Penerapan Sistem Informasi Manajemen Kepegawaian (SIMPEG) Di Badan Kepegawaian Daerah (BKD) Kabupaten Sidoarjo," Inspirasi Manaj. Pendidik., 2018, [Online].

https://jurnalmahasiswa.unesa.ac.id/index.php/i nspirasi-manajemenpendidikan/article/viewFile/24239/22165.

[27] I. P. G. Astawa, I. G. M. Darmawiguna, "Evaluasi Usability Sistem Informasi Kepegawaian Kabupaten Badung (Simpeg Badung) Menggunakan Metode Usability Testing (studi kasus: SMP Negeri 3 Petang)," KARMAPATI, vol. 8, no. 2, pp. 209-223, 2019, https://ejournal.undiksha.ac.id/index.php/KP/ar ticle/view/18325.

[28] D. Novianto, "Implementasi Sistem Informasi Pegawai (Simpeg) Berbasis Web Menggunakanframework Codeigniter Dan Bootstrap," Ilm. Inform. Glob., vol. 7, no. 1, pp. 10-16, 2016, http://ejournal.uigm.ac.id/index.php/IG/article/ view/153.

[29] Athin Pratiwi, "Implementasi Sistem Informasi Manajemen Kepegawaian ( Simpeg) Sebagai Dasar Pengambilan Keputusan Bidang Sumber Daya Manusia ( Sdm )," J. Mhs. Adm. Negara (JMAN), Vol. 02 No. O2, Oktober 2018 ISSN 2222-3333|, vol. 02, no. 02, p. 12, 2018.

[30] F. Ferdous, M. M. Chowdhury, and F. Bhuiyan, "Barriers to the Implementation of Human Resource Information Systems," Asian J. Manag. Sci. Educ., vol. 4, no. January, pp. 3342, 2015.

[31] Kuspriyomurdono, Deputi Bidang Bina Kinerja dan Perundang-undangan Badan Kepegawaian Negara Jakarta, 2013.

[32] M. Mukarramah and T. S. Arbani, "Pengawasan Pegawai Negeri Sipil Melalui Sistem Informasi Manajemen Kepegawaian (Simpeg)," Alauddin Law Dev. J., vol. 2, no. 2, 2020, http://103.55.216.56/index.php/aldev/article/vie w/15411.

[33] Keputusan Menteri Dalam Negeri Nomor 17 Tahun 2000 Sistem Informasi Manajemen Kepegawaian Departemen Dalam Negeri dan Pemerintah Daerah. Indonesia, 2000. 